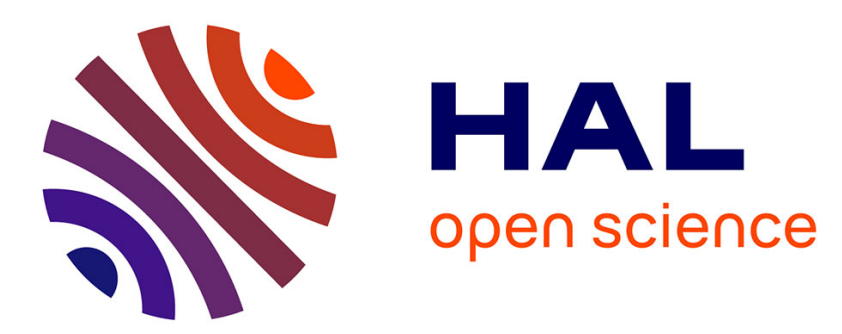

\title{
Infectivity of pestivirus following persistence of acute infection.
}

Margaret E. Collins, Judith Heaney, Carole J. Thomas, Joe Brownlie

\section{To cite this version:}

Margaret E. Collins, Judith Heaney, Carole J. Thomas, Joe Brownlie. Infectivity of pestivirus following persistence of acute infection.. Veterinary Microbiology, 2009, 138 (3-4), pp.289. 10.1016/j.vetmic.2009.04.022 . hal-00514612

\section{HAL Id: hal-00514612 \\ https://hal.science/hal-00514612}

Submitted on 3 Sep 2010

HAL is a multi-disciplinary open access archive for the deposit and dissemination of scientific research documents, whether they are published or not. The documents may come from teaching and research institutions in France or abroad, or from public or private research centers.
L'archive ouverte pluridisciplinaire HAL, est destinée au dépôt et à la diffusion de documents scientifiques de niveau recherche, publiés ou non, émanant des établissements d'enseignement et de recherche français ou étrangers, des laboratoires publics ou privés. 


\section{Accepted Manuscript}

Title: Infectivity of pestivirus following persistence of acute infection.

Authors: Margaret E. Collins, Judith Heaney, Carole J.

Thomas, Joe Brownlie

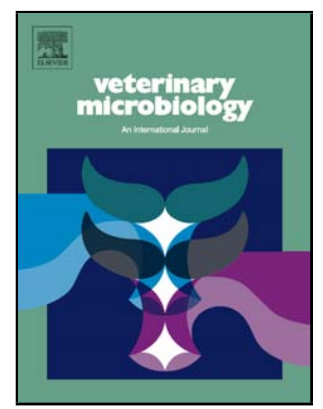

PII:

S0378-1135(09)00185-0

DOI: doi:10.1016/j.vetmic.2009.04.022

Reference: VETMIC 4412

To appear in:

Received date: $\quad 15-10-2008$

Revised date: 26-3-2009

Accepted date: $\quad 3-4-2009$

Please cite this article as: Collins, M.E., Heaney, J., Thomas, C.J., Brownlie, J., Infectivity of pestivirus following persistence of acute infection., Veterinary Microbiology (2008), doi:10.1016/j.vetmic.2009.04.022

This is a PDF file of an unedited manuscript that has been accepted for publication. As a service to our customers we are providing this early version of the manuscript. The manuscript will undergo copyediting, typesetting, and review of the resulting proof before it is published in its final form. Please note that during the production process errors may be discovered which could affect the content, and all legal disclaimers that apply to the journal pertain. 
1 Infectivity of pestivirus following persistence of acute infection.

2

3 Margaret E. Collins, ${ }^{2}$, Judith Heaney, ${ }^{1,2}$, Carole J. Thomas ${ }^{\#}$ and Joe Brownlie.

4 Department of Pathology and Infectious Diseases

5 The Royal Veterinary College

6 Hawkshead Lane

7 North Mymms

8 Hatfield

9 Hertfordshire

10 AL9 7TA

11 \# Corresponding author: Carole J. Thomas

12 Tel : 01707666211

13 Email : cthomas@rvc.ac.uk

14 Running title: Pestivirus infectivity after persistence of acute infection.

$16{ }^{1}$ Current address: Division of Transfusion Medicine, Dept of Haematology, University of Cambridge,

17 Long Road, Cambridge, CB2 2PT

$18{ }^{2}$ Dr Collins and Dr Heaney made different but equal contributions to this work and are considered joint

19 first authors.

20 Abstract

21 Bovine viral diarrhoea virus (BVDV) is an endemic pathogen worldwide and eradication strategies

22 focus on identification and removal of persistently infected (PI) animals arising after in utero infection.

23 Despite this, acute infections with BVDV can persist for months or years after the removal of the PI

24 source despite repeated screening for PIs and tight biosecurity measures. Recent evidence for a

25 prolonged duration of viraemia in the testicles of bulls following acute BVDV infection suggests the 
1 possibility of a form of chronic persistence that may more closely resemble the persistence strategies of

2 hepatitis $\mathrm{C}$ virus (HCV).

3

4 To investigate the potential for virus transmission from infected and recovered cattle to virus naïve

5 hosts we established an acute infection of 5 BVDV naïve calves and monitored animals over 129 days.

6 Infectious BVDV was detected in white blood cells between days 3 and 7 post-challenge. The animals

7 seroconverted by day 21 post-infection and subsequently were apparently immune and free from

8 infectious virus and viral antigen.

9

10 Animals were further monitored and purified white blood cells were stimulated in vitro with

11 phytohaemagglutinin A (PHA) during which time BVDV RNA was detected intermittently.

12

13 Ninety eight days following challenge, blood was transferred from these apparently virus free and

14 actively immune animals to a further group of 5 BVDV naïve calves and transmission of infection was

15 achieved. This indicates that BVDV-infected, recovered and immune animals have the potential to

16 remain infectious for BVDV-naïve cohorts for longer than previously demonstrated.

\section{Keywords}

18 BVDV, pestivirus, acute infection, long term persistence, transmission, infectivity. 


\section{Introduction}

3

4 As members of the Flaviviridae, pestiviruses are enveloped RNA viruses with a positive sense $12.5 \mathrm{~kb}$

5 genome encoding 11 or 12 proteins (Collett et al., 1988), (Elbers et al., 1996) with related viruses

6 infecting cattle, sheep and pigs. The type member of this genus is bovine viral diarrhoea virus (BVDV).

7 The similarities between BVDV and human hepatitis C virus (HCV) are in many ways greater than

8 their relationship to other members of the Flaviviridae as both have similar genome structure and

9 organisation, similarities in their replication strategies and the ability to cause long term infection of

10 their hosts. These similarities have led to many studies using BVDV as a model for HCV infection.

$12 \mathrm{BVDV}$ is endemic in most countries and the consequences of infection in terms of the economic impact

13 and animal welfare are highly significant (Houe, 2003). The observed range of clinical outcomes

14 largely depends upon the characteristics of the infecting virus (Bolin and Ridpath, 1992), (Brownlie,

15 1991) and consequences of infection include decreased milk yield, poor reproductive performance, loss

16 of condition and high levels of recurrent infection due to the immunosuppressive effects of

17 BVDV-associated leucopenia. Haemorrhagic strains of BVDV, which are endemic throughout North

18 America and Canada and increasingly apparent in mainland Europe (Vilcek et al., 2005) also cause

19 high mortality and severe loss of condition during the acute infection (Brownlie, 1991), (Pellerin et al.,

20 1994), (Ridpath et al., 2000). As the animal welfare and economic implications of unchecked infection

21 become apparent, many countries (including Austria, Denmark, Finland, Germany, Norway, Sweden)

22 are undertaking the national eradication of BVDV. 
1 The typical course of acute infection of postnatal animals (cattle or sheep) has been well defined

2 experimentally (Howard, 1990) identifying a period of viraemia between 4 and 10 days post infection

3 during which infectious BVDV can be detected in serum, blood, buffy coat cells and nasal secretions.

4

5 A transient pyrexia and a significant leucopenia is seen between days 3 and 10 post infection.

6 Seroconversion can be detected, rarely at day 7 but more usually by day 14 . As active immunity

7 develops virus spread is eliminated and infectious virus is rarely detected in buffy coat cells or nasal

8 secretions beyond 14 days. In this respect, acute BVDV infection seemed to be resolved much more

9 readily than $\mathrm{HCV}$ infection which is known to persist in a significant number of infected individuals

10 (Tester et al., 2005; Thimme et al., 2001). The use of more sensitive detection techniques such as

11 RT-PCR can extend the period when BVDV RNA can be detected but isolation of infectious virus is

12 generally not possible beyond 14 to 21 days post infection as the animal develops significant levels of

13 anti-viral neutralising antibodies which continue to increase in titre beyond 40 to 50 days post

14 infection.

16 A further consequence of acute infection with BVDV occurs when the period of active viraemia occurs

17 during the first trimester of pregnancy. In these circumstances, virus can cross the placenta and

18 establish extensive viraemia within the immuno-incompetent foetus. Many such infections result in

19 abortion but up to $60 \%$ will survive to produce a calf which is persistently infected (PI),

20 immunotolerant to the virus and will actively shed virus throughout its life (Brownlie, 1990).

21

22 To date, the persistently infected, immunotolerant animal has been considered to be the major source of BVDV spread and eradication schemes have focussed on the identification and culling of such animals

24 (Houe, 1999). However, many units have experienced great difficulty in eliminating the circulation of

25 BVDV even in the absence of PI animals and the presence of tight biosecurity measures (Houe, 1999). 
2 These observations have prompted attempts to identify a previously unrecognised form of viral

3 persistence in acutely infected and antibody positive animals. A number of authors (including

4 (Ssentongo et al., 1980), (Grooms et al., 1998), (Niskanen et al., 2002), (Givens et al., 2003)) have

5 reported detection of BVDV in reproductive tissues (ovary, testis or semen) of cattle at prolonged times

6 following initial acute infection: in ovarian tissue 60 days following challenge (Grooms et al., 1998)

7 and in semen up to 7 months after initial infection with a live BVDV vaccine. These authors (Givens et

8 al., 2003) were unable to culture virus directly from semen but could detect viral RNA by nested

9 RT-PCR and did transmit virus to one calf of three following intravenous injection of semen collected

10 at 5 months post infection.

12 With the exclusion of the known incidents of BVDV transmission in virus-infected semen, it was not

13 clear whether these animals with long term persistence of viral antigen in their ovaries or testes were

14 infectious for BVDV naïve herd mates. To our knowledge, there is no published report of BVDV

15 immune animals transmitting infectious virus except through semen. The reports of long term

16 persistence of viral antigen in ovaries or detection or viral RNA in white blood cells (unpublished

17 observations) cannot yet be equated with infectivity and the status of these animals is unresolved.

19 Similar questions are raised for HCV. Recent publications of Pham et al. (Pham et al., 2005), (Pham et

20 al., 2004) which confirm that for HCV, ex vivo stimulation of PBMCs with mitogens and cytokines will

21 stimulate the previously undetectable replication of viral RNA in both lymphocytes and dendritic cells

22 of infected patients. Questions have been raised as to whether such cases represent the detection of

23 "occult RNA" or whether there is the real potential for virus infectivity and transmission in these

24 samples (Quiroga and Carreno, 2005; Quiroga et al., 2006). A recent paper by Gogorza et al. (Gogorza

25 et al., 2005) has also indicated that ex vivo stimulation of PBMCs from cattle in a number of BVDV 
1 antibody positive herds was successful in producing antigen-positive samples and infectious virus from

2 a small number of individual cattle but in this field situation it was not possible to comment on the

3 infection history of these individuals within the herds. Although antibody levels could be measured, it

4 was impossible to know when the individuals had been exposed to virus or the duration of persistence

5 and again, the potential for spread of infectious virus was not assessed.

6

7 In the light of these observations a review of the pathogenesis of acute BVDV infections is essential as

8 the virus-free status of antibody positive, immune animals can no longer be assumed. Important

9 questions remain:

10 - does infectious virus persist more widely in recovered, immune and apparently virus free cattle?

11 - can this virus be transmitted to BVDV-naïve herdmates?

12 To this end, we undertook an experimental study of the longer term detection of BVDV following

13 acute infection and the potential for virus transmission from immune animals.

15 In the following paper we describe the infection of BVDV naïve calves with a noncytopathogenic

16 strain of BVDV and attempts to transfer infection from recovered animals to further BVDV-naïve

17 cattle. The hypothesis underlying this study is that BVDV can persist, long-term, following acute

18 infection of the post natal immunocompetent animal and is transmissible to BVDV naive herdmates. 


\section{Materials \& Methods}

3

4 Study design: Five BVDV antibody- and antigen-free calves (numbers 321, 330, 339, 345 and 360:

5 study group A), of approximately three months of age sourced from a BVDV-free herd, were

6 challenged intranasally with $10 \mathrm{ml}$ of isolate $\$ 456497$ (5 x $10^{6}$ TCID $\left._{50}\right)$, a type 1a BVDVnc identified

7 as a more clinically virulent field isolate (T. Drew, VLA, personal communication). This infectious

8 dose has been shown to be effective in previous studies (Brownlie et al., 1995). See Fig 1 for summary

9 of experimental outline. Blood samples (plain clotted and EDTA) were taken by jugular venepuncture

10 at regular intervals (on days $-2,-1,0,4,5,6,7,8,11,14,21,28,35,42,49,56,63,70,77,84,91,98$,

$11105,112,119,126,133,140,147$ and 154 where day 0 is the day of virus challenge).

12

13 At day 77 two additional BVDV naïve calves (399 and 408) were introduced to the group to ascertain

14 the potential for horizontal transmission of viral infection and were also sampled on study days 84, 91

15 and 98 together with the original calves.

17 On study day 98 a further 3 BVDV naïve calves were introduced to the group (467, 469 and 473). At

18 this stage, $20 \mathrm{ml}$ blood from the original group of 5 calves (study group A: numbers 321, 330, 339, 345

19 and 360) was injected, $10 \mathrm{ml}$ intravenously and $10 \mathrm{ml}$ subcutaneously, into the younger animals (399,

20 408, 467, 469 and 473: study group B). Sampling of all calves continued on study days 112, 119 and

21126 after which time the older, study group A calves were removed from the study. The remaining

22 study group B calves were sampled again on study days 133, 140, 147 and 154 when the study ended.

24 Virus isolation: Following purification of the buffy coat cells from EDTA blood by ammonium

25 chloride lysis, virus was isolated by co-culture of white blood cells (WBCs) with uninfected foetal 
1 bovine lung (FBL) cells followed by immunodetection of the virus as described previously (Nobiron et 2 al., 2003).

3

4 BVDV antibody ELISA: A BVDV antibody ELISA was performed using prepared antigen from cells 5 infected with the cytopathic BVDV strain NADL (also using mock-infected cells as a negative control) 6 as previously described (Howard et al, 1985).

7 NS3 indirect antibody ELISA: The NS3 antigen used in this assay (Young et al., 2005) was captured

8 from a lysate obtained from NADL infected FBL cells using the monoclonal antibody WB112

9 (Veterinary Laboratories Agency) diluted 1:100 in carbonate coating buffer (Sigma). Uninfected cells

10 were also prepared as a negative background controlThe ELISA plate was blocked with 5\% NPS

11 before positive and negative antigen was added. Test sera were added, diluted 1:50 and binding

12 detected using biotinylated monoclonal anti-bovine IgG clone BG18 (Sigma) followed by incubation

13 with Streptavidin-horseradish peroxidase conjugate (Amersham Biosciences). The ELISA was

14 developed with OPD substrate (Sigma) and optical density measured using an Optimax microplate

15 reader (Molecular Diagnostics) at 490nm using SOFTmax ${ }^{\circledR P R O ~ v e r s i o n ~ 5.0 . ~}$

17 E2 antibody ELISA: The E2 antigen for the detection of anti-E2 antibodies was recombinant

18 his-tagged protein expressed from a baculovirus system (Nobiron et al., 2003) and diluted in carbonate

19 buffer. Plates were washed and blocked with 5\% NPS. Test sera were added and binding of bovine IgG

20 was detected as above.

21

Ex vivo stimulation of PBMCs: PBMCs were isolated from EDTA blood (5 ml) by density gradient centrifugation using Histopaque1083. Leucocytes were removed from the top of the Histopaque cushion and washed in $20 \mathrm{ml}$ of ice cold PBS. Any remaining red blood cells were lysed by briefly

25 resuspending the pellet in $2 \mathrm{ml}$ of sterile ultrapure water before adding $20 \mathrm{ml}$ of PBS and washing twice 
1 in PBS. The cells were finally resuspended in $10 \mathrm{ml}$ of pre-warmed RPMI-1640 medium (Sigma)

2 containing 10\% FCS, glutamine $200 \mathrm{mM}$, penicillin $100 \mathrm{IU} / \mathrm{ml}$ and streptomycin $100 \mu \mathrm{g} / \mathrm{ml}$ with

3 phytohaemagglutinin (PHA, Sigma L8754, $5 \square \mathrm{g} / \mathrm{ml}$ ) for 72-hours. After stimulation, PBMCs were

4 pelleted by centrifugation at $400 \mathrm{xg}, 4{ }^{\circ} \mathrm{C}$ for 10 minutes before RNA extraction.

5

6 RNA extraction, RT-PCR and sequencing: Total RNA was extracted from potentially virus infected

7 cells using of $0.8 \mathrm{ml}$ of RNA Stat-60 (AMS Biotechnology ltd, UK) according to the manufacturer's

8 instructions. RNA was precipitated from the aqueous phase with $0.5 \mathrm{ml}$ of isopropanol and $1 \mu 1$ of

9 glycogen $\left(20 \mathrm{mg} / \mathrm{ml}\right.$, Roche Diagnostics, USA) at $4{ }^{\circ} \mathrm{C}$ for $30 \mathrm{~min}$ and then collected by centrifugation.

10 The RNA pellet was washed in $1 \mathrm{ml}$ of $75 \%$ ethanol and resuspended in $50 \mu \mathrm{l}$ of diethylpyrocarbonate

11 (DEPC)-treated ultrapure water.

12

13 RNA was reverse transcribed (RT) to cDNA with random hexamer primers, $(50 \mathrm{ng} / \mu \mathrm{l}$, Amersham

14 Biosciences, UK) and Superscript II, reverse transcriptase (200 units/ $\mu$, Invitrogen) according to the

15 manufacturer's instructions. The reactions were held at $42{ }^{\circ} \mathrm{C}$ for $50 \mathrm{~min}$ and at $70{ }^{\circ} \mathrm{C}$ for a final 15

$16 \min$.

17

18 cDNA ( $5 \mu \mathrm{l})$ generated by RT was amplified by PCR ( $0.5 \mu \mathrm{l}$ of $P f u$ polymerase ( 5 units/ $\mu$, Promega),

$192.5 \mu \mathrm{l}$ of 10X buffer (Promega), $1 \mu 110 \mathrm{mM}$ dNTPs, using $2.5 \mu \mathrm{l}$ primer 324 and $2.5 \mu \mathrm{l}$ primer 326

20 (Vilcek, 1994), both at $10 \mathrm{pmol} / \mathrm{ml}$, in a final volume of $20 \mu \mathrm{l}$ with sterile ultrapure water. These

21 primer sequences are highly conserved in different BVDV isolates and amplify a 288-bp fragment of

22 the 5' untranslated region of the BVDV genome. This fragment was sequenced using Cy-5 labelled

23 primers and a Thermosequenase kit on an Amersham Biosciences ALF Express DNA analyser. 
1 A negative control was provided by a 'no template' reaction, with sterile ultrapure water added. For

2 positive controls cDNA generated from foetal bovine lung cells (FBLs) infected with BVDV isolate 3 Ky1203nc was used.

4 5 


\section{Results}

3

4 Virus challenge: Back titration of the type 1a BVDVnc isolate $\$ 456497$ challenge inoculum confirmed

5 that all study group A calves (numbers 321, 330, 339, 345 and 360) received a high infectious dose of 6 approximately $5 \times 10^{6} \mathrm{TCID}_{50}$.

7

8 Clinical responses to virus challenge were recorded from day -1 to day 12. All calves experienced 9 some degree of pyrexia, peaking around day 8 or 9 post infection and leucopenia between days 3 and

1014 (data not shown). Both of these are typical signs of BVDV infection. Additionally, the calves were

11 observed for clinical signs of disease. Occasional coughing was noted, but calves appeared healthy in

12 all other respects.

13

14 Seroconversion: A total anti-BVDV antibody ELISA was performed to detect BVDV-specific (total

$15 \mathrm{IgG}$ ) antibodies in the serum. The results (Fig 2) indicate that by day 21 post challenge all calves had 16 seroconverted to BVDV, showing a positive ELISA result. Antibody titres continued to rise from day

1721 , and for 4 animals was still increasing in titre up to day 105 post challenge. The group A calves were

18 removed from the study at day 129 post challenge at which time all five showed antibody titres that

19 would indicate a high degree of protection to infection with BVDV.

20

21 Virus isolation: Infectious virus was isolated from PBMCs by co-culture with FBL cells and detected

22 by immunostaining. The results (table 1) indicate that infectious BVDV was isolated from every calf

23 between days 3 to 7, with some individual variation in the timing of viraemia. All animals were

24 apparently virus-free by standard virus isolation techniques by day 10 post challenge and evidence for 
1 the onset of seroconversion by day 14. No infectious virus was isolated directly from purified PBMCs

2 after day 10 post infection.

3

4 Stimulation of PBMCs using PHA and viral RNA detection: At days 28, 42, 56, 63, 70, 77, 84, 91 and

598 post challenge PBMCs purified from the five, study group A calves were stimulated by incubation

6 with the mitogen PHA before cells were used for conventional virus isolation or for RNA extraction

7 followed by RT-PCR.

8

9 Between days 28 and 98 post infection viral RNA was detected in PBMCs on a number of occasions in

10 each animal (table 2). This was evident in unstimulated PBMCs in 16 separate samples and following

11 stimulation of PBMCs with PHA for $72 \mathrm{hr}$, viral RNA was detected in 26 different samples indicating

12 that stimulation did increase the frequency of RNA detection. No infectious virus was recovered from

13 any of these samples following immunostaining using standard protocols (data not shown).

15 Virus transmission: To assess the potential for horizontal transmission of BVDV, on day 77, BVDV

16 naïve calves 399 and 408 were introduced into the existing group and monitored weekly for any signs

17 of virus transmission. During a three week period the new animals were consistently virus negative by

18 virus isolation and RT-PCR and did not seroconvert to BVDV (data not shown).

20 On study day 98, a further 3 BVDV-naïve calves (467, 469 and 473), were introduced to the group and

21 exchange of blood from study group A (numbers 321, 330, 339, 345 and 360) to study group B (399,

22 408, 467, 469 and 473) was undertaken. Both groups were subjected to continued monitoring for virus

23 isolation, RT-PCR and seroconversion after sampling at weekly intervals. 
1 During the next 28 days, animals in study group A were consistently negative for virus isolation and

2 continued to demonstrate high levels of circulating anti-BVDV antibodies (Fig 2b). Study group A 3 animals were removed from the study on day 129 , four weeks after the transmission of blood to study 4 group B animals.

5

6 Animals in study group B were observed to seroconvert to BVDV, beginning at day 14 post blood 7 transmission (animal 408) and all group B animals were seropositive in the standard BVDV antigen 8 ELISA by study day 140, 42 days following blood exchange between group A and group B animals

9 (Fig 4). To ensure that this was a result of active virus replication in group B animals and not the 10 passive transfer of antigen, seroconversion to recombinant BVDV E2 glycoprotein and to the BVDV

11 non-structural protein NS3 were measured independently and antibody levels increased in all animals 12 over the 42 day period of observation (Fig 3).

14 Viral RNA was detected in purified PBMCs of animal 469 on day 7 post transmission, with other 15 group B animals, except 408, being virus RNA positive up to 21 days post infection (table 3 ). Sequence 16 analysis of the RT-PCR product (corresponding to the viral 5 ' untranslated region), indicated that the 17 recovered virus from 469 was identical to that of the original challenge virus over the range of bases 18 sequenced (data not shown). Only animal 408 appeared to be virus free by these methods but did show 19 the strongest seroconversion to BVDV in all three ELISA assays (for total anti-BVDV, anti-E2 and anti-NS3 antibody). 


\section{Discussion}

3 The hypothesis underlying this study was that BVDV can persist, long-term, following acute infection 4 of the immunocompetent animal and be transferred to BVDV-naïve herdmates. That BVDV has the 5 ability to cause persistent infection, a lifelong viraemia following in utero infection of the developing 6 foetus, is well-established. In contrast, BVDV infection of the post natal animal has been regarded as

7 an acute event, being cleared from the blood within just 14 days. This clearance of viraemia has been

8 assumed to represent clearance of infection, with seroconversion indicating long-term protection from

9 disease. However, the results from this study have satisfied the hypothesis, showing for the first time

10 that BVDV can be transmitted to BVDV-naïve hosts by transfer of blood 98 days after the initial

11 challenge event.

12

13 Relatively few published studies of acute BVDV infection have followed the time course of infection

14 beyond day 21-28 post-challenge as all the available evidence suggested that virus had been eliminated

15 before this time. However, it has now been shown that the RNA of BVDV can be detected in PBMCs

16 for prolonged periods when infectious virus cannot be recovered. Although unexpected, this parallels

17 the situation where HCV RNA can be carried in the PBMCs for at least five years after spontaneous or

18 treatment-induced resolution of disease (Pham et al., 2004) and again highlights similarities between

19 these two viruses. Another study was able to detect BVDV antigen in PBMCs of seropositive cattle

20 and to recover infectious virus in vitro following mitogenic stimulation ex vivo (Gogorza et al., 2005).

21 As cattle in this study were in a field situation it was impossible to estimate the original time of

22 exposure of the cattle to live virus or draw conclusions about the duration of persistence of BVDV

23 infection in these animals. 
1 These observations support reports of the detection of persistent viral antigen in reproductive tissues

2 following acute BVDV infection (Ssentongo et al., 1980), (Grooms et al., 1998) (Givens et al., 2003),

3 (Niskanen et al., 2002). The unanswered question remains as to whether such animals are infectious for

4 herdmates by other methods than transfer of semen.

5

6 In other systems, longer term persistence of respiratory syncytial virus antigen has been associated with

7 hyper-responsiveness and inflammation (Bramley et al., 1999) which exacerbates the disease state. In

8 contrast most cases of acute BVDV infection seem to be resolved with few serious clinical

9 consequences for the individual although the consequences for both the herd and for the business may

10 often be underestimated. It is many years since long term circulation of parainfluenza virus infection

11 was first described in completely enclosed communities at the South Pole (Muchmore et al., 1981).

12 This persistence of acute infection in the absence of re-introduction of additional sources of infection

13 provides precedent for our investigation. The defects in protective immunity and the pathogenesis

14 strategies of viruses for immuno-evasion and immuno-modulation which allow virus persistence are

15 still only partly described.

17 The current study provided a more extensive time course following BVDV infection.

18 We were unable to demonstrate horizontal transmission of the virus to BVDV naïve calves housed for

193 weeks with the seropositive, infectious virus-negative but RNA positive study group A animals in

20 agreement with other studies describing poor transmission from acutely infected animals. Direct

21 contact with an immunotolerant persistently infected animal has been shown to be a more efficient

22 means of infection although even then, less so than the consistently high transmission of virus achieved

23 when subcutaneous injection occurs transferring blood or serum or on needles used with shared BVDV

24 contaminated vials, even through use of contaminated rectal examination gloves (Cook et al., 1990),

25 (Lang-Ree et al., 1994; Niskanen and Lindberg, 2003). Similarly in the current study, transfer of 20ml 
1 of blood from the apparently virus free and immune group A calves to five BVDV naïve group B

2 calves resulted in the effective transmission of virus to the new hosts. Seroconversion was, relatively

3 speaking, a slower and less synchronous event than normal, perhaps reflecting the fact that variable

4 amounts of virus were transmitted in each inoculum as has been reported previously when different

5 sources of virus and differing routes of transmission were compared (Cook et al., 1990). While blood

6 transfer was an "artificial" procedure, it does genuinely represent the possibility of exchange of blood

7 or fluids through biting flies (Tarry et al., 1991) or other veterinary intervention (Lang-Ree et al.,

8 1994), (Niskanen and Lindberg, 2003).

9

10 We cannot absolutely determine whether virus spread to all of the group B calves is as a result of

11 transmission through blood or horizontal transmission within the group. Calves 408 and 469

12 seroconverted rapidly (day 14 and 21) suggesting that these animals were infected initially. As animal

13473 was RT-PCR positive by day 7 post blood transfer (7 days is not usually regarded as sufficient time

14 for seroconversion following horizontal transmission from calves 408 and 469) this suggests that three

15 of the five calves were directly infected by transmission via blood transfer. Calves 467 and 473 were

16 both RNA positive by day 21 post transmission but showed a slower seroconversion, 42 days post

17 blood transfer and it is impossible to assess whether their infection arose following blood transfer or

18 horizontal transmission from other calves in the group in the current study.

20 It is certain that transmission from BVDV-infected, seropositive and apparently virus free cows did

21 occur, probably 98 days after the original infection. It is also possible that in the natural farm environment, stress or concurrent infection may act as a stimulus for virus recrudescence and increase the levels of viraemia in seropositive, recovered cattle making transmission to BVDV-naïve herdmates more likely, a possibility which is worthy of future study. 
1 The significance of these results is that long-term persistence of infectious BVDV following acute

2 viraemia has the potential to hinder BVDV control efforts worldwide and would constitute a

3 mechanism whereby BVDV is maintained within a population over a long period of time, despite the

4 removal of all PI animals. Animals known to have seroconverted to the virus following natural

5 infection, and hence assumed protected could instead act as long-term virus carriers. Replication during

6 this period may be continuous, spontaneous, or it may require a stimulus, such as stress caused by

7 crowding, intercurrent disease or transportation perhaps explaining the role of BVDV in shipping fever

8 (Fulton et al., 2000). In the current study, young calves were challenged with BVDV. A possibility for

9 the prolonged residence of the virus in the young/neonate animal is that the immune response may not

10 be sufficiently mature to remove all virus (Pollock at al., 1991). Against this proposal is the observation

11 that foetuses in late gestation (the last trimester) are able to clear the virus and make an active immune

12 response; such calves have never, to our knowledge, been examined for 'occult' virus. If young calves,

13 however, were found to be more liable to a persistent acute infection, it could have implications for the

14 use of modified-live virus vaccines.

17 As the group A animals had high titres of circulating antibody at the time of blood exchange it remains

18 a possibility that vaccination against BVDV may not be sufficient to overcome pre-existing persistence

19 of the virus in animals that had already been naturally infected. This observation highlights the

20 importance of being able to readily discriminate between naturally infected and vaccinated cattle.

21

22 Further studies are required to elucidate the frequency and duration of long term persistence in

23 naturally infected cattle, the sites and mechanisms of virus persistence and possible stimuli for

24 recrudescence. It will be of the utmost importance to determine the potential for infectious virus

25 dissemination from virus positive, seropositive cattle to BVDV naïve animals in natural environments. 


\section{Acknowledgements}

3 We would like to thank Dr Trevor Drew at the Veterinary Laboratories Agency for the field strain

$4 \$ 456497$ used in these studies. This work was supported by internal research group funds.

5 
1 Bolin, S.R., Ridpath, J.F., 1992, Differences in virulence between two noncytopathic bovine viral diarrhea viruses in calves. Am J Vet Res 53, 2157-2163.

Bramley, A.M., Vitalis, T.Z., Wiggs, B.R., Hegele, R.G., 1999, Effects of respiratory syncytial virus persistence on airway responsiveness and inflammation in guinea-pigs. Eur Respir J 14, 1061-1067.

Brownlie, J., 1990, Pathogenesis of mucosal disease and molecular aspects of bovine virus diarrhoea virus. Vet Microbiol $23,371-382$

Brownlie, J., 1991, The pathways for bovine virus diarrhoea virus biotypes in the pathogenesis of disease. Arch Virol Suppl $3,79-96$

Brownlie, J., Clarke, M.C., Hooper, L.B., Bell, G.D., 1995, Protection of the bovine fetus from bovine viral diarrhoea virus by means of a new inactivated vaccine. Vet Rec 137, 58-62.

Collett, M.S., Larson, R., Belzer, S.K., Retzel, E., 1988, Proteins encoded by bovine viral diarrhea virus: the genomic organization of a pestivirus. Virology $165,200-208$.

Cook, L.G., Littlejohns, I.R., Jessep, T.M., 1990, Induced sero-conversion in heifers with a field strain of bovine pestivirus-a comparison of methods and doses. Aust Vet J 67, 393-395.

5 Elbers, K., Tautz, N., Becher, P., Stoll, D., Rumenapf, T., Thiel, H.J., 1996, Processing in the pestivirus E2-NS2 region: identification of proteins p7 and E2p7. J Virol 70, 4131-4135.

Fulton, R.W., Purdy, C.W., Confer, A.W., Saliki, J.T., Loan, R.W., Briggs, R.E., Burge, L.J., 2000, Bovine viral diarrhea viral infections in feeder calves with respiratory disease: interactions with Pasteurella spp., parainfluenza-3 virus, and bovine respiratory syncytial virus. Can J Vet Res 64, 151-159.

Givens, M.D., Heath, A.M., Brock, K.V., Brodersen, B.W., Carson, R.L., Stringfellow, D.A., 2003, Detection of bovine viral diarrhea virus in semen obtained after inoculation of seronegative postpubertal bulls. Am J Vet Res 64, 428434.

Gogorza, L.M., Moran, P.E., Larghi, J.L., Segui, R., Lissarrague, C., Saracco, M., Braun, M., Esteban, E.N., 2005, Detection of bovine viral diarrhea virus (BVDV) in seropositive cattle. Prev Vet Med 72, 49-54; discussion 215219.

Grooms, D.L., Brock, K.V., Ward, L.A., 1998, Detection of bovine viral diarrhea virus in the ovaries of cattle acutely infected with bovine viral diarrhea virus. J Vet Diagn Invest 10, 125-129.

Houe, H., 1999, Epidemiological features and economical importance of bovine virus diarrhoea virus (BVDV) infections. Vet Microbiol 64, 89-107.

Houe, H., 2003, Economic impact of BVDV infection in dairies. Biologicals 31, 137-143. 
1 Howard, C.J., 1990, Immunological responses to bovine virus diarrhoea virus infections. Rev Sci Tech 9, 95-103.

Howard CJ, Clarke MC, Brownlie J. An enzyme-linked immune-sorbent assay (ELISA) for the detection of antibodies to bovine viral diarrhoea virus (BVDV) in cattle sera. Vet Microbiol 1985; 10: 359-69.

Lang-Ree, J.R., Vatn, T., Kommisrud, E., Loken, T., 1994, Transmission of bovine viral diarrhoea virus by rectal examination. Vet Rec 135, 412-413.

Muchmore, H.G., Parkinson, A.J., Humphries, J.E., Scott, E.N., McIntosh, D.A., Scott, L.V., Cooney, M.K., Miles, J.A., 1981, Persistent parainfluenza virus shedding during isolation at the South Pole. Nature 289, 187-189.

Niskanen, R., Alenius, S., Belak, K., Baule, C., Belak, S., Voges, H., Gustafsson, H., 2002, Insemination of susceptible heifers with semen from a non-viraemic bull with persistent bovine virus diarrhoea virus infection localized in the testes. Reprod Domest Anim 37, 171-175.

Niskanen, R., Lindberg, A., 2003, Transmission of bovine viral diarrhoea virus by unhygienic vaccination procedures, ambient air, and from contaminated pens. Vet J 165, 125-130.

Nobiron, I., Thompson, I., Brownlie, J., Collins, M.E., 2003, DNA vaccination against bovine viral diarrhoea virus induces humoral and cellular responses in cattle with evidence for protection against viral challenge. Vaccine 21, 20822092.

Pellerin, C., van den Hurk, J., Lecomte, J., Tussen, P., 1994, Identification of a new group of bovine viral diarrhea virus strains associated with severe outbreaks and high mortalities. Virology 203, 260-268.

Pham, T.N., Macparland, S.A., Coffin, C.S., Lee, S.S., Bursey, F.R., Michalak, T.I., 2005, Mitogen-induced upregulation of hepatitis C virus expression in human lymphoid cells. J Gen Virol 86, 657-666.

Pham, T.N., MacParland, S.A., Mulrooney, P.M., Cooksley, H., Naoumov, N.V., Michalak, T.I., 2004, Hepatitis C virus persistence after spontaneous or treatment-induced resolution of hepatitis C. J Virol 78, 5867-5874.

Pollock, J.M., Rowan, T.G., Dixon, J.B., Carter, S.D., Kelly, D.F., 1991, Estimation of immunity in the developing calf: cellular and humoral responses to the keyhole limpet haemocyanin. Vet Immunol Immunopathol 29, 105-113.

Quiroga, J.A., Carreno, V., 2005, HCV-indeterminate blood donors or occult HCV infection? Lancet 365, 1540-1541; author reply 1541 .

Quiroga, J.A., Llorente, S., Castillo, I., Rodriguez-Inigo, E., Lopez-Alcorocho, J.M., Pardo, M., Carreno, V., 2006, Virusspecific T-cell responses associated with hepatitis $\mathrm{C}$ virus (HCV) persistence in the liver after apparent recovery from HCV infection. J Med Virol 78, 1190-1197.

Ridpath, J.F., Neill, J.D., Frey, M., Landgraf, J.G., 2000, Phylogenetic, antigenic and clinical characterization of type 2 BVDV from North America. Vet Microbiol 77, 145-155. 
1 Ssentongo, Y.K., Johnson, R.H., Smith, J.R., 1980, Association of bovine viral diarrhoea-mucosal disease virus with 2 ovaritis in cattle. Aust Vet J 56, 272-273.

3 Tarry, D.W., Bernal, L., Edwards, S., 1991, Transmission of bovine virus diarrhoea virus by blood feeding flies. Vet Rec

4 $128,82-84$.

5 Tester, I., Smyk-Pearson, S., Wang, P., Wertheimer, A., Yao, E., Lewinsohn, D.M., Tavis, J.E., Rosen, H.R., 2005, Immune evasion versus recovery after acute hepatitis C virus infection from a shared source. J Exp Med 201, 1725-1731.

7 Thimme, R., Oldach, D., Chang, K.M., Steiger, C., Ray, S.C., Chisari, F.V., 2001, Determinants of viral clearance and 8 persistence during acute hepatitis C virus infection. J Exp Med 194, 1395-1406.

9 Vilcek, S., 1994, [Development of PCR tests for the detection of bovine herpesvirus-1, bovine respiratory syncytial viruses and pestiviruses]. Vet Med (Praha) 39, 687-700.

11 Vilcek, S., Durkovic, B., Kolesarova, M., Paton, D.J., 2005, Genetic diversity of BVDV: consequences for classification and molecular epidemiology. Prev Vet Med 72, 31-35; discussion 215-219.

13 Young, N.J., Thomas, C.J., Thompson, I., Collins, M.E., Brownlie, J., 2005, Immune responses to non-structural protein 3 (NS3) of bovine viral diarrhoea virus (BVDV) in NS3 DNA vaccinated and naturally infected cattle. Prev Vet Med 72, 115-120; discussion 215-119.

16 
1 Figure legends:

2 Figure 1. Summary of the sampling schedules for the study.

3

4 Figure 2. Seroconversion following challenge of Group A calves

5 Serum antibody titres to total BVDV antigen were measured in all five calves using an antibody

6 capture ELISA following challenge with BVDV isolate \$456497. A standard curve using a reference

7 BVDV hyperimmune serum allowed the results to be expressed as units/ml (Howard et al., 1985).

8 Clear evidence of seroconversion (90 to 180 antibody units) was seen by day 21 post infection (panel a)

9 and titres continued to rise in all animals (4,500 to 44,000 antibody units) at least up to day 105 post

10 challenge (panel b).

12 Figure 3. Seroconversion of study Group B animals following transfer of blood.

a) Total anti-BVDV antibody. Early seroconversion is noted in calf 408 by day 14 post transfer with all animals becoming seropositive (over 100 units) by day 42 .

b) Anti-E2 antibody. Using an ELISA to purified recombinant E2, the major structural glycoprotein, again animal 408 becomes seropositive by day 14 post transfer with other animals seroconverting later.

c) Anti-NS3 antibody. Using an ELISA to purified recombinant NS3, four animals are clearly seropositive by day 42 post transfer while anti-NS3 titres in animal 467 are still increasing. 
Introduce 3

naïve calves.

Transfer

blood to

Challenge

Introduce 2

Group B

calves.

Group A

calves

removed.

Study terminated.

calves.

$35 \quad 49$

$63 \quad 77$

$91 \quad 105$

119

133

147

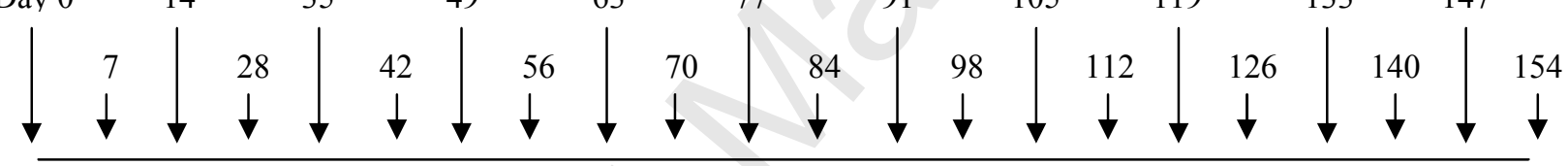

Figure 1. 
a)

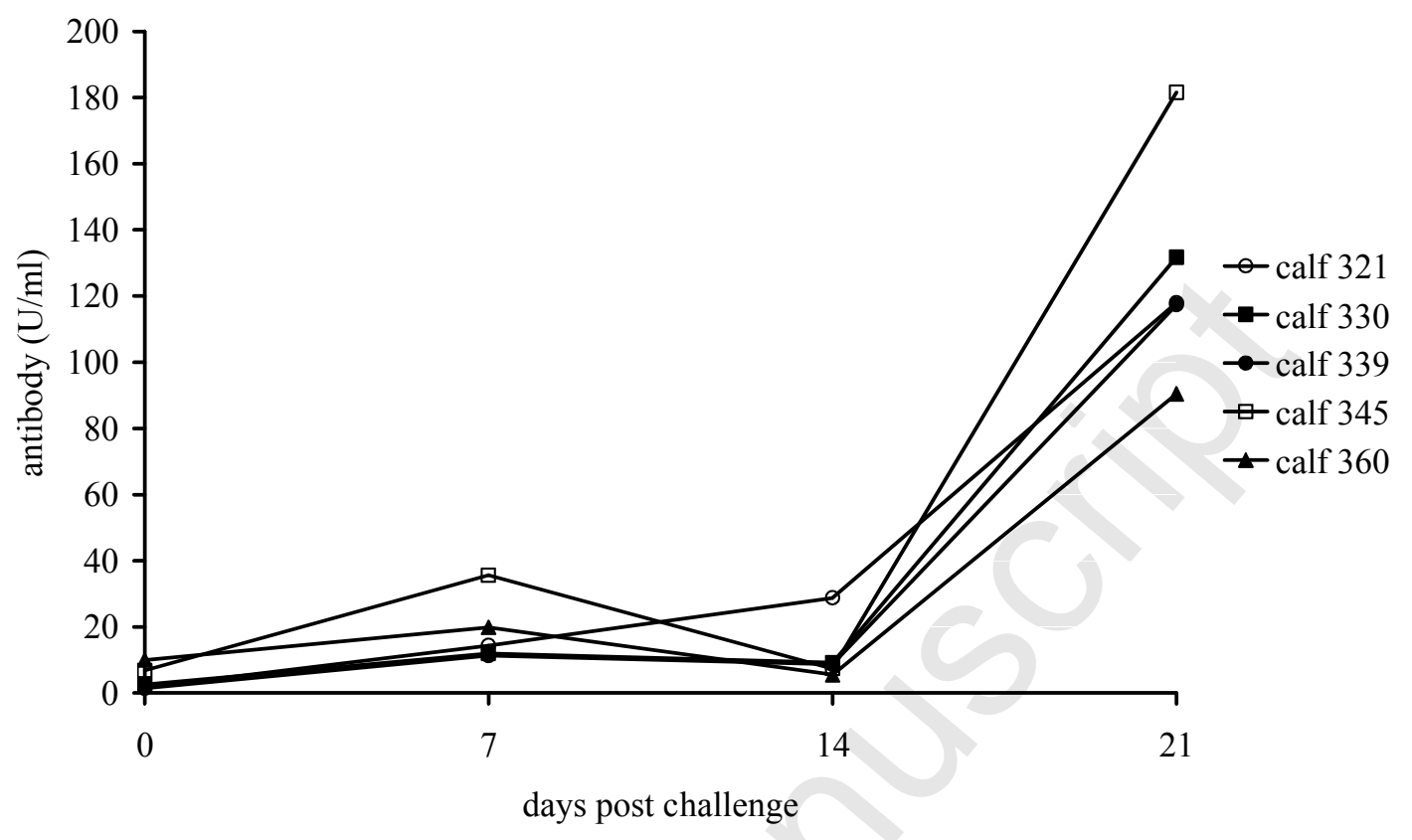

b)

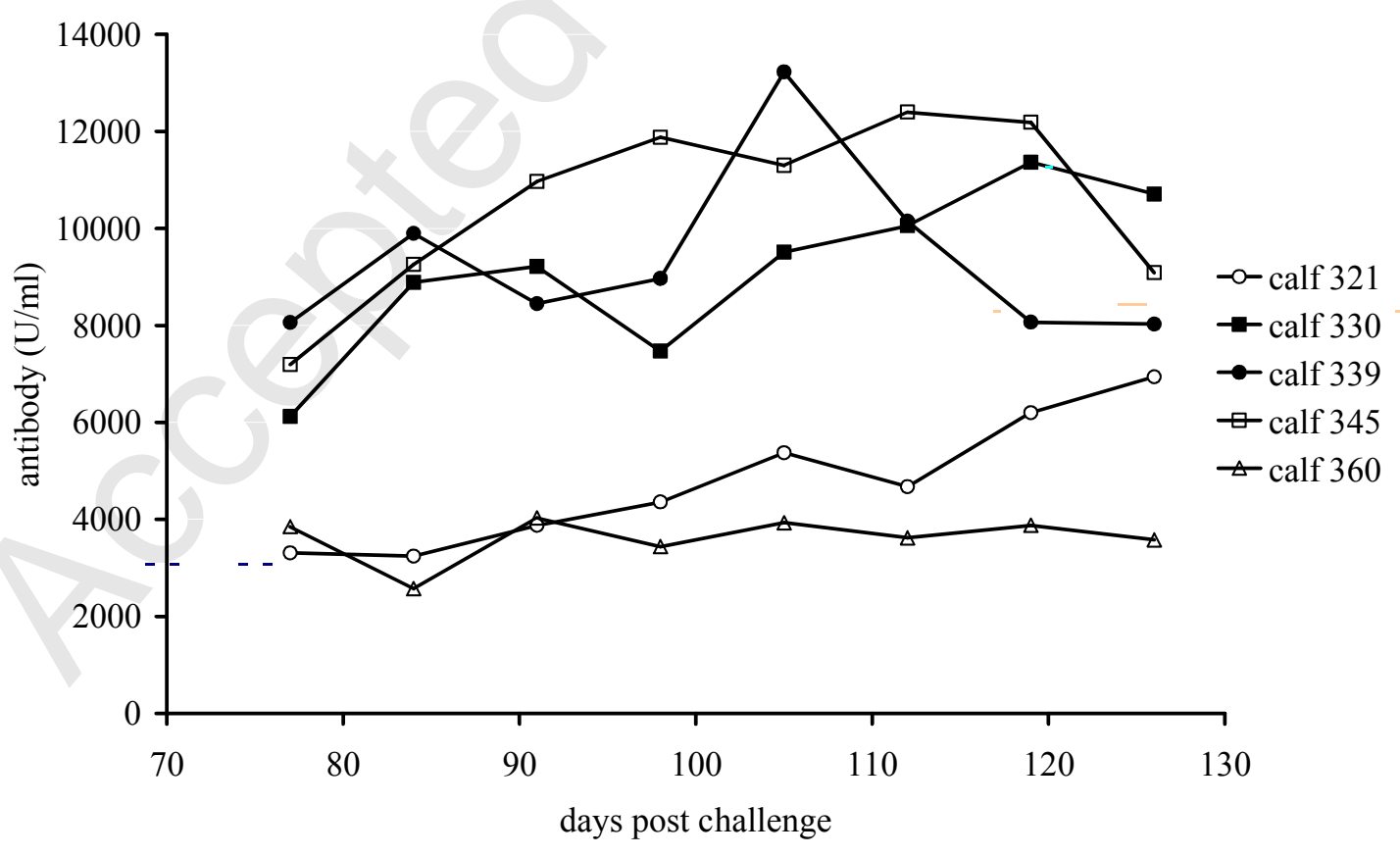

Figure2 
a)

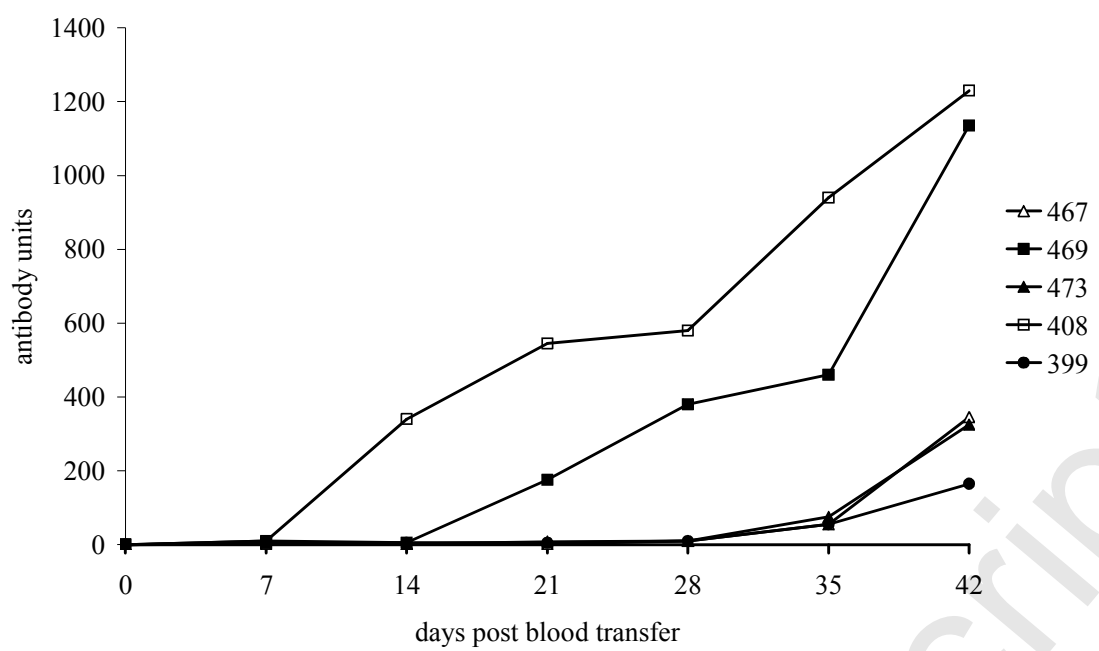

b)

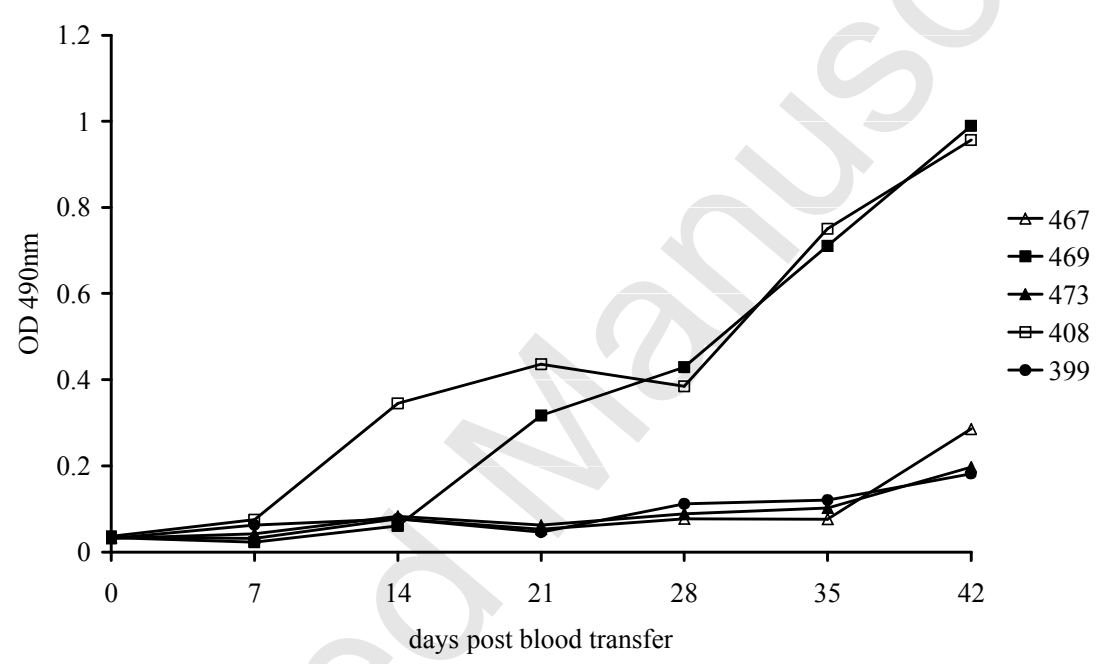

c)

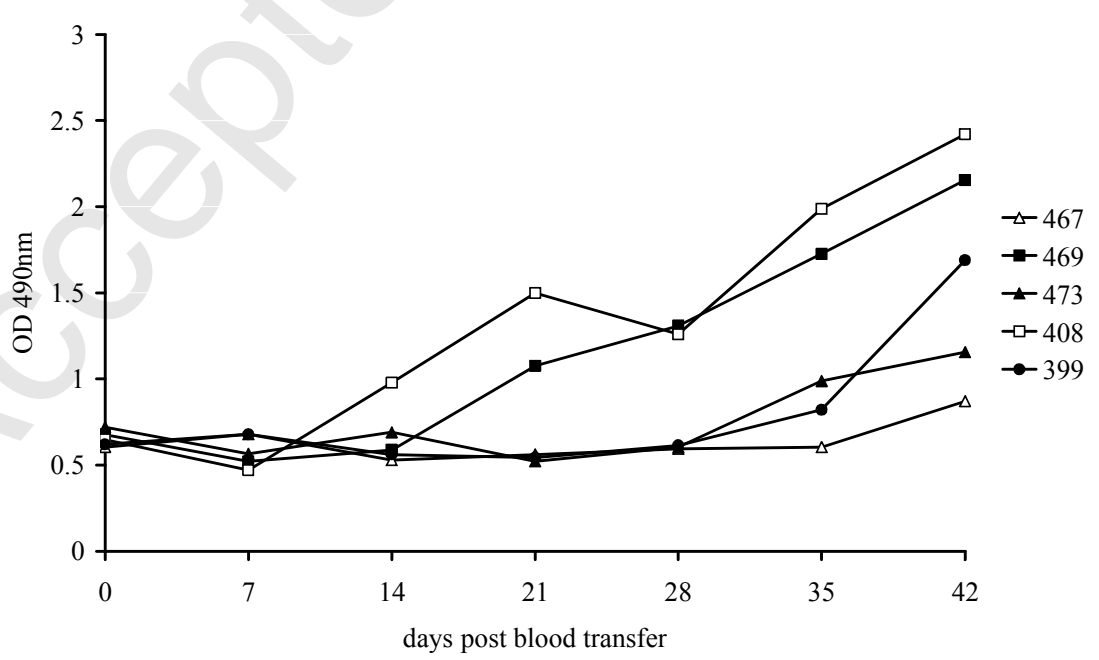

Figure3. 


\begin{tabular}{|c|c|c|c|c|c|}
\hline Calf number & 321 & 330 & 339 & 345 & 360 \\
\hline Study Day & & & & & \\
\hline 0 & - & - & - & - & - \\
\hline 3 & - & - & + & - & + \\
\hline 5 & + & + & + & + & + \\
\hline 6 & + & + & + & - & + \\
\hline 7 & - & + & + & + & + \\
\hline 10 & - & - & - & - & - \\
\hline 14 & - & - & & - & - \\
\hline 21 & - & - & t & - & - \\
\hline
\end{tabular}

Table 1. BVDV virus isolation from white blood cells between study days 0 and 21 .

The buffy coat cell population from all calves challenged with BVDV isolate $\$ 456497$ was purified from whole blood as described and the cell lysate co-cultured with foetal bovine lung cells for two passages before virus antigen was detected using a standard immunofluorescence assay. Unambiguous staining for viral antigen was seen as early as day three post challenge in calves 339 and 360 and all five calves were virus positive on day 5. By day 10 post infection all calves were definitely virus negative in this assay. 


\begin{tabular}{||c|c|c|c|c|c|c|c|c|c|c||}
\hline $\begin{array}{c}\text { Animal } \\
\text { number }\end{array}$ & \multicolumn{2}{|c|}{321} & \multicolumn{2}{|c|}{330} & \multicolumn{2}{|c|}{339} & \multicolumn{2}{|c|}{345} & \multicolumn{2}{|c||}{360} \\
\hline $\begin{array}{c}\text { Days post } \\
\text { infection }\end{array}$ & NS & S & NS & S & NS & S & NS & S & NS & S \\
\hline 28 & + & + & + & + & + & + & - & + & - & + \\
\hline 42 & - & - & - & - & - & + & - & + & - & + \\
\hline 56 & + & + & + & + & + & + & + & + & + & + \\
\hline 63 & + & + & - & + & + & + & + & + & + & + \\
\hline 70 & - & - & - & - & - & - & - & - & - & - \\
\hline 77 & - & - & - & - & - & - & - & - & - & + \\
\hline 84 & - & - & - & - & - & - & - & - & - & - \\
\hline 91 & + & + & & + & & + & + & + & + & + \\
\hline 98 & - & - & - & + & - & - & - & + & + & - \\
\hline \hline
\end{tabular}

Table 2. Detection of virus specific RNA by RT-PCR in PBMCs of study group A animals.

$\mathrm{NS}=$ nonstimulated PBMCs

$\mathrm{S}=$ PHA stimulated PBMCs

$+=$ RNA detected by RT-PCR

- = RNA not detected by RT-PCR 


\begin{tabular}{||c|c|c|c|c|c|c|c|c|c|c||}
\hline $\begin{array}{l}\text { Animal } \\
\text { number }\end{array}$ & \multicolumn{2}{|c|}{399} & \multicolumn{2}{|c|}{408} & \multicolumn{2}{c|}{467} & \multicolumn{2}{c||}{469} & \multicolumn{2}{|c}{473} \\
\hline $\begin{array}{l}\text { Days post } \\
\text { blood } \\
\text { transmission }\end{array}$ & NS & S & NS & S & NS & S & NS & S & NS & S \\
\hline 7 & - & - & - & - & - & - & - & - & + & - \\
\hline 14 & - & - & - & - & - & - & - & - & - & - \\
\hline 21 & + & - & - & - & + & - & - & + & + & + \\
\hline
\end{tabular}

Table 3. Detection of virus specific RNA by RT-PCR in PBMCs of study group B animals.

$\mathrm{NS}=$ nonstimulated PBMCs

$\mathrm{S}=$ PHA stimulated PBMCs

$+=$ RNA detected by RT-PCR

- = RNA not detected by RT-PCR 